ICAMS $2016-6^{\text {th }}$ International Conference on Advanced Materials and Systems

\title{
STUDY ON OBTAINING KERATIN EXTRACTS FROM LEATHER
} INDUSTRY BY-PRODUCTS

\author{
MIHAELA-DOINA NICULESCU, MARIANA DANIELA BERECHET, CARMEN GAIDĂU, \\ MĂDĂLINA IGNAT, MIHAI RADU \\ INCDTP - Division Leather and Footwear Research Institute, 93 Ion Minulescu St, Bucharest, \\ Romania,icpi@icpi.ro
}

\begin{abstract}
Keratin is a biopolymer with numerous functional properties for the production of biomaterials with applications such as: additives for cosmetics, biostimulator for growth and nutrition in agriculture, ecological treatments in reconstruction and protection of leather and furs, as alternative to pollutant chemical compounds. In most of the applications, in either large or niche industries, keratin is used as gels, films, nano- or micro-particles. This study presents the possibilities of using thermal and enzymatic processes of leather industry by-products to obtain keratin extracts. Keratin extracts were characterized by chemical and instrumental analyses: gravimetric, volumetric, potentiometry, Polyacrylamide Gel Electrophoresis, Infrared Spectroscopy, High-Performance Liquid Chromatography, Dynamic Light Scattering. Analytical investigation has shown that the keratin extracts obtained as polydispersions with 5\% dry matter have 14\% total nitrogen and contain $50 \%$ small and medium sized particles (10-500 $\mathrm{nm}$ range), such as free amino acids and oligopeptides and $50 \%$ larger sized particles $(500-5560 \mathrm{~nm}$ ranges) such as polypeptides. The IR spectrum of keratin extract is similar to the IR spectrum of collagen from leather.
\end{abstract}

Keywords: keratin, molecular weight, amino acids

\section{INTRODUCTION}

Obtaining keratin hydrolysates from by-products/waste from the leather industry contributes to the recovery of these natural resources, to the reduction of the amount of stored waste and to environmental pollution prevention. The hydrolysates may be used to develop new biomaterials with multiple applications, as well as to design environmentally-friendly treatments for leather and fur with various functionalities.

Wool is a keratinous material with specific structure, mechanical behaviour and physical-chemical properties (Wang et al., 2016). A clean wool fibre contains approximately $82 \%$ keratinous protein with high concentration of cysteine, approximately $17 \%$, a protein material with a low cysteine content called "nonkeratinous material" mainly localized in the complex of the cell membrane and approximately $1 \%$ of the non-protein material is made up of waxy lipids, plus a small amount of polysaccharide material (Lewis and Rippon, 2013).

Keratins are the most abundant structural proteins in epithelial cells and, together with collagen, it forms the most important biopolymer in the organic matter that constitutes animal tissue (Coulombe and Omary, 2002; McKittrick et al., 2012). Keratin is among the most rigid biological materials, with high hardness and elastic modulus, although is is made up only of polymer compounds and rarely contains minerals (Wegst and Ashby, 2004; Szewciw et al., 2010).

Keratinous materials are high in cysteine, which differentiates them from other biopolymers, are usually durable, rigid and non-reactive with the natural environment. They provide mechanical support and various protection functions in the adaptation of vertebrates to the external environment (Schweizer et al., 2006).

Extraction of keratin from wool can be achieved in various ways, all of them involving the presence of reduction or distortion agents to break disulfide bonds (Aldemar et al., 2005; Liu et al., 2004; Aluigi et al., 2007). 
Keratin extracts are obtained using acid hydrolysis (Khosa and Ullah, 2014), hydrolysis in alkaline medium (Hill et al., 2010; Staron et al., 2014), enzymatic hydrolysis (Krejci et al., 2011) and ionic liquid extraction (Ji et al., 2014). The various methods of obtaining keratin extracts lead to variations in their composition and properties. These differences allow the use of keratin hydrolysates in the production of materials with multiple industrial applications, in agriculture and niche applications.

This study proposes to transform a low economic value material (sheep wool scraps) into a product with potential for exploitation in various fields: leather processing, cosmetics, agriculture, as wool is a source of organic nitrogen as macronutrient but also sulfur as essential mesonutrient for plant nutrition (for example, in leguminous plants sulfur deficiency leads to reduction of nodules on the roots, increase of soluble nitrogen and slow formation of protein substances).

\section{EXPERIMENTAL}

\section{Materials}

Raw materials: wool by-products from the leather industry with the following characteristics: dry substance, max. $87 \%$; ash, max. 13\%; total nitrogen, min. $13 \%$.

Auxiliary materials: ammonia, 25\% solution, CAS 1336-21-6; detergent; anhydrous sodium carbonate, CAS 497-19-8; distilled water; hydrated lime, p.a.; rotulis sodium hydroxide; potassium hydroxide, p.a.

\section{Procedures}

In order to obtain keratin extracts, raw wool (LB) was degreased in a FAVE vessel system using a solution of $1 \mathrm{~g} / \mathrm{L}$ of $25 \%$ ammonia, detergent and sodium carbonate anhydrous, under stirring for 12 hours at $35^{\circ} \mathrm{C}$.

After degreasing, the wool was dried in a ventilated open space and then fragmented.

Degreased wool (LD) was subjected to alkaline hydrolysis: (a) with $10 \%$ hydrated lime (b) with 5\% sodium hydroxide, (c) with 5\% potassium hydroxide and keratin hydrolysates were obtained according to the technological scheme of Fig. 1.

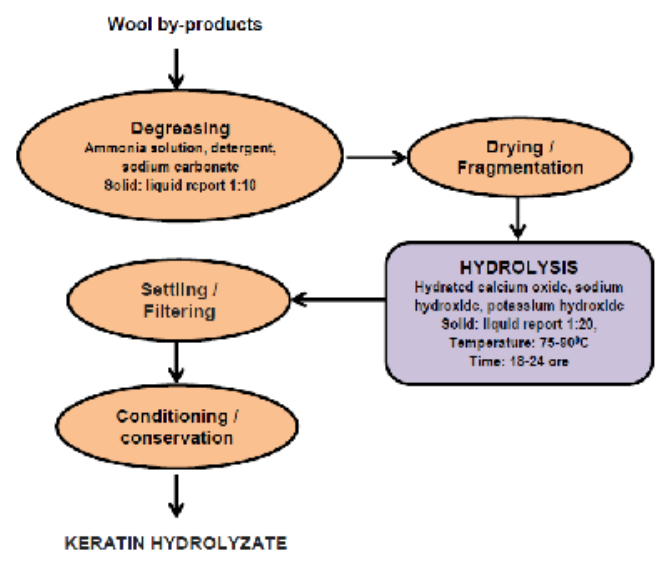

Figure 1. Technological scheme for obtaining keratin hydrolysates 
ICAMS $2016-6^{\text {th }}$ International Conference on Advanced Materials and Systems

\section{Analytical Methods}

The keratin extracts were analysed in terms of dry substance and total ash by gravimetric methods, total nitrogen and protein substance, aminic nitrogen by volumetric methods, $\mathrm{pH}$ by potentiometric method, molecular weight by SDS-PAGE electrophoresis. Particle size and distribution was determined by ZetaSizer device Nano ZS (Malvern, UK), IR spectral analysis by FT/IR-4200 (Jasco) with ATR device equipped. Static contact angle of keratine hydrolysate was evaluated with contact angle analysis equipment, VGA Optima XE system, AST Products SUA.

\section{RESULTS AND DISCUSSIONS}

Keratin hydrolysates with distinct colors were obtained depending on the alkaline hydrolysis medium: (a) clear orange (KHA1), (b) brown (KHA2), (c) tan (KHA3). The unsolubilized wool residue has a different appearance and consistency: a) RL1, from the hydrolysis with calcium oxide has a brittle consistency, b) RL2 from the hydrolysis with sodium hydroxide is compact and has a more rigid consistency, c) RL3 from hydrolysis with potassium hydroxide is voluminous and thick.

Keratin hydrolysates obtained by alkaline hydrolysis were analyzed in terms of chemical and physical-chemical properties and specific properties were identified, using different instrumental techniques: electrophoresis, DLS, IR spectroscopy.

Physico-chemical analyses showed significant and close values for total nitrogen, which reveals extraction of large amounts of proteins (Fig. 2). Proteinaceous material is between $65.29 \%$ (KHA3) and 79.02\% (KHA1), and the amino nitrogen up to $3.21 \%$ (KHA1). The high values of ash range between $12.28 \%$ (KHA1) amd 25.62\% (KHA3), showing that the keratin hydrolysates are rich in minerals used in hydrolysis $(\mathrm{Ca}, \mathrm{Na}, \mathrm{K})$.

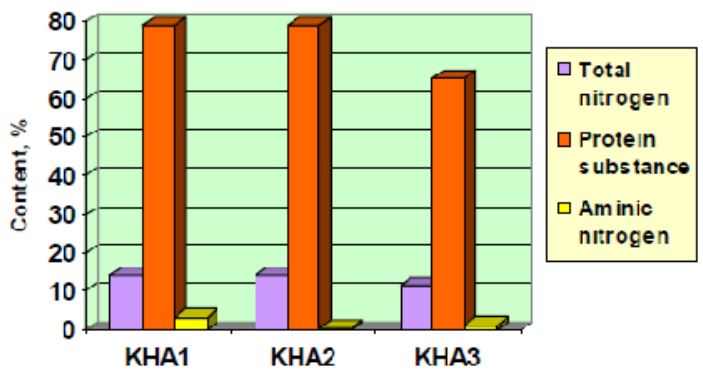

Figure 2. Protein composition of keratin hydrolysates

Determining Distribution of Molecular Weights in Keratin Hydrolysates by SDS PAGE Electrophoresis

The electrophoretic pattern of keratin is associated with two main groups of protein specific to keratin, intermediate filamentous proteins and matrix proteins.

Figure 3 shows the distribution of molecular masses in keratin hydrolysates experimentally obtained by alkaline hydrolysis from wool by-products. 


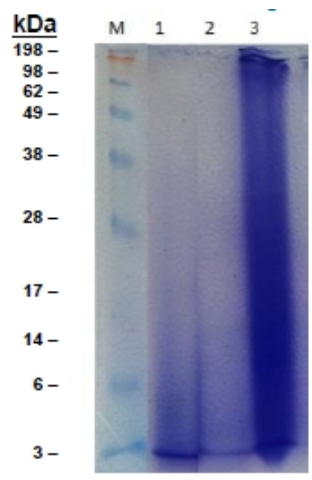

Figure 3. Distribution of molecural weights in keratin hydrolysates: M-marker;1-KHA1; 2-KHA2; 3-KHA3

Two high molecular weight bands are visible $(45-60 \mathrm{kDa})$ attributed to filamentous proteins with a low sulfur content and more low molecular weight bands attributed to proteins with a high content of sulfur (20-10 kDa) and a high content of glycine/tyrosine (6-9 kDa) (Vasconcelos et al., 2008). These considerations highlight the presence of proteins with a high content of sulfur (20-10 kDa) but rich in glycine/tyrosine (6-9 kDa) with low molecular weight, mainly in keratin hydrolysate (KHA1), but also in keratin hydrolysate (KHA3). Proteins with a low sulfur content and high molecular weight assigned to filamentous proteins are more evident in keratin hydrolysate (KHA3).

\section{Determining Particle Sizes Using Dynamic Light Scattering (DLS)}

Measurements of the intensity of reflected light indicate a narrow spectrum of particle sizes for the three types of keratin hydrolysate, Figure 4, including mostly medium-sized particles in the range of $100-1000 \mathrm{~nm}$, specific to oligopeptides and larger peptides.

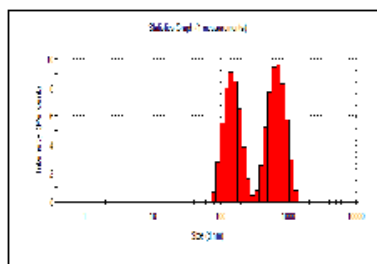

(a)

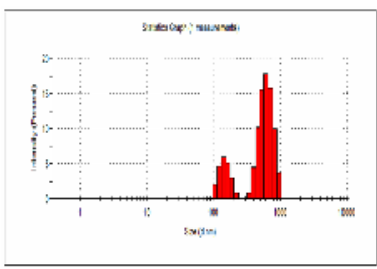

(b)

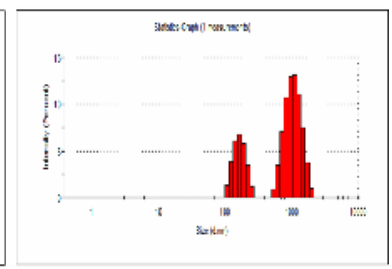

(c)

Figure 4. Particle size distribution in keratin hydrolysates: (a) KHA1, obtained with hydrated lime; (b) KHA2, obtained with sodium hydroxide; (c) KHA3, obtained with potassium hydroxide

However, the KHA1 hydrolysate also contains smaller particles in the higher area of the 10-100 nm range, specific to amino acids and small oligopeptides, but also a small percentage of particles greater than $1000 \mathrm{~nm}$, namely polypeptides. Hydrolysates KHA2 and KHA3 do not have particles smaller than $100 \mathrm{~nm}$, however, hydrolysate KHA3 
ICAMS $2016-6^{\text {th }}$ International Conference on Advanced Materials and Systems

shows a higher percentage of particles of over $1000 \mathrm{~nm}$. These data are consistent with results of electrophoresis which reveal the presence of compounds with molecular weights lower than $20 \mathrm{KDa}$, and some compounds with molecular weight higher than $45 \mathrm{KDa}$.

\section{Structural Analysis of Keratin Hydrolysates Using FT-IR Spectroscopy}

Infrared absorption spectra of keratin hydrolysates (KHA1, KHA2, KHA3) show characteristic bands attributed both to peptides (-CONH) of amide I, amide II, and amide III types, and to sulfur compounds.

Among these, there are bands specific to primary amides at $3400 \mathrm{~cm}^{-1}$ and secondary amides at $3440 \mathrm{~cm}^{-1}$ attributable to the stretching vibration $v_{\mathrm{N}-\mathrm{H}}$ and the band specific to tertiary amides at $1650 \mathrm{~cm}^{-1}$ attributable to the stretching vibration $v_{\mathrm{C}=\mathrm{O}}$, present in the three spectra of keratin hydrolysates (Fig. 5). The bands at $600-700 \mathrm{~cm}^{-1}$ attributed to stretching vibration $v_{\mathrm{C}-\mathrm{S}}$ and at $800-900 \mathrm{~cm}^{-1}$ attributed to rocking vibration $\delta_{\mathrm{S}-\mathrm{H}}$ are specific to sulfur compounds (Khosa and Ullah, 2014; Hill et al., 2010; Staron et al., 2014).

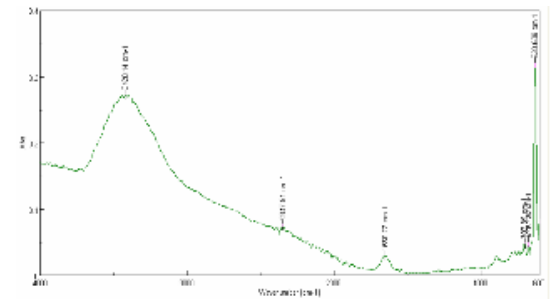

(a)

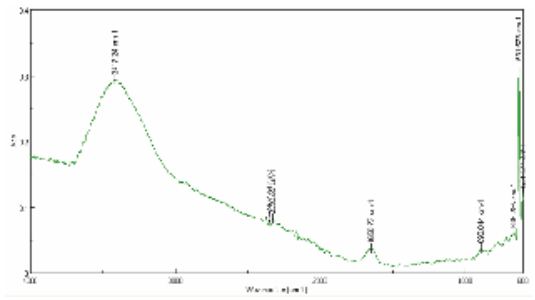

(b)

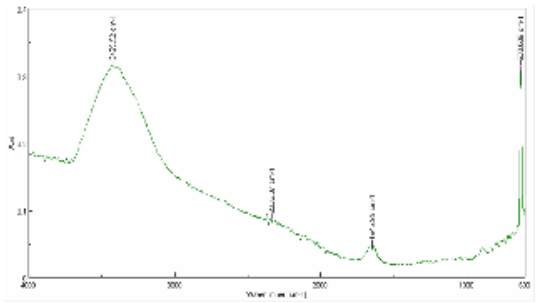

(c)

Figure 5. FT-IR spectral analysis of keratin hydrolysates: (a) KHA1; (b) KHA2; (c) KHA3

\section{Determination of Contact Angle and Surface Tension of Keratin Hydrolysates}

Determining the contact angle value of keratin hydrolysates, in relation to glass as inert material indicates a strongly hydrophilic behavior, recording very low values: $9.25^{\circ}$ for KHA $1,7.75^{\circ}$ for KHA2, $6.32^{\circ}$ for KHA3. These hydrophilic contact angles are the premises for good adhesion of keratin hydrolysates to non-hydrophobic porous surfaces, for example, unfinished tanned leather or plant seeds.

Surface tension values of keratin hydrolysates: $40.77 \mathrm{~mJ} / \mathrm{m}^{2}$ for KHA1, $46.49 \mathrm{~mJ} / \mathrm{m}^{2}$ for KHA2, $46.18 \mathrm{~mJ} / \mathrm{m}^{2}$ for KHA3, confirm the presence of low intermolecular forces that cause a high capacity for wetting surfaces. 


\section{CONCLUSIONS}

Keratin extracts were obtained from wool by-products from the leather and fur industry, through alkaline hydrolysis.

Extracting keratin from by-products contributes to decreasing the amount of byproducts stored and prevents pollution, while recovering and reusing residual protein as eco-friendly products for applications in industry and in bio-economy.

Using keratin extracts in agriculture has the advantage of providing organic nitrogen as macronutrient and sulfur as mesonutrient.

\section{Acknowledgements}

The authors gratefully acknowledge the financial support of the ANCSI and UEFISCDI, Romania, in the framework of projects PN 16.34.01.11 (contr. no. 26N/2016) and COLL_LEG_SEED (contr. no. 7/2016).

\section{REFERENCES}

Alemdar, A., Iridag, Y., and Kazanci, M. (2005), "Flow behavior of regenerated wool-keratin proteins in different mediums", International Journal of Biological Macromolecules, 35, 151-153.

Aluigi, A., Zoccola, M., Vineis, C., Tonin, C., Ferrero, F., and Canetti, M. (2007), "Study on the structure and properties of wool keratin regenerated from formic acid", International Journal of Biological Macromolecules, 41(3), 266-273.

Coulombe, P.A., and Omary, M.B. (2002), “'Hard' and 'soft' principles defining the structure, function and regulation of keratin intermediate filaments", Current Opinion in Cell Biology, 14(1), 110-22.

Hill, P., Brantley, H., and Van Dyke, M. (2010), "Some properties of keratin biomaterials: Kerateines", Biomaterials, 31, 585-593.

Ji, Y., Chen, J., Lv, J., Li, Z., Xing, L., and Ding, S. (2014), "Extraction of keratin with ionic liquids from poultry feather", Separation and Purification Technology, 132, 577-583.

Khosa, M.A., and Ullah, A. (2014), "In-situ modification, regeneration, and application of cheratin biopolymer for arsenic removal", Journal of Hazardous Materials, 278, 360-371.

Krejci, O., Mokrejs, P., and Sukop, S. (2011), "Preparation and characterization of keratin hydrolysates", in Mathematical Methods and Techniques in Engineering and Environmentyal Science: Proceedings of the 13th WSEAS International Conference on Mathematical and Computational Methods in Science and Engineering, 308-311.

Lewis, D.M., and Rippon, J.A., editors (2013), The coloration of wool and other keratin fibres, John Wiley.

Liu, Y., Shao, Z., Zhou, P. and Chen, X. (2004), "Thermal and crystalline behaviour of silk fibroin/nylon 66 blend films", Polymer, 45, 7705-7710.

McKittrick, J., Chen, P.Y., Bodde, S.G., Yang, W., Novitskaya, E.E., and Meyers, M.A. (2012), "The structure, functions, and mechanical properties of keratin", The Journal of The Minerals, Metals \& Materials Society, 64(4), 449-68.

Schweizer, J., Bowden, P.E., Coulombe, P.A., Langbein, L., Lane, E.B., Magin, T.M. et al. (2006), "New consensus nomenclature for mammalian keratins", The Journal of Cell Biology, 174(2), 169-74.

Staron, P., Banach, M., Kowalski, Z., and Staron, A. (2014), "Hydrolysis of keratin materials derived from poultry industry", Proceedings of ECOpole.

Szewciw, L.J., de Kerckhove, D.G., Grime, G.W., and Fudge, D.S. (2010), "Calcification provides mechanical reinforcement to whale baleen alpha-keratin", Proceedings of the Royal Society B: Biological Sciences, 277(1694), 2597-605.

Vasconcelos, A., Freddi, G., Cavaco-Paulo, A. (2008), "Biodegradable Materials Based on Silk Fibroin and Keratin”, Biomacromolecules, 9, 1299-1305.

Wang, B., Yang, W., McKittrick, J., and Meyers, M.A. (2016), "Keratin: Structure, mechanical properties, occurrence in biological organisms, and efforts at bioinspiration", Progress in Materials Science, 76, 229318.

Wegst, U.G.K., and Ashby, M.F. (2004), "The mechanical efficiency of natural materials", Philosophical Magazine, 84(21), 2167-86. 